\title{
Decisional Profile on Competing Volleyball Athletes From Autonomous University of Chihuahua (Uach): Gender Comparison
}

\author{
Dr. Juan Cristobal Barron Lujan, \\ Silvia Isela Ramírez Enríquez, M.P.P., \\ Héctor Luis Medina Lopez, M.A.R.H., \\ Francisco Javier Flores Rico, M.C., \\ Gilberto Santos Sambrano, M.P.A., \\ Leopoldo Refugio Lopez Baca, M.C., \\ Dr. Gabriel Gastelum Cuadras, \\ Faculty of Physical Culture Sciences, \\ Autonomous University of Chihuahua, Mexico
}

\begin{abstract}
Sports psychology considers the athlete as an individual capable of processing information and making their own decisions which reflects in the results obtained as a team in a competition within the sports environment. This paper focuses on comparing the competing decisional profile on the sports performance of volleyball players at the Autonomous University of Chihuahua and also determines gender differences. For this, a descriptive, comparative investigation was carried out, where 24 representative athletes of the university participated in this discipline. Here, the questionnaire of Decision Style in the Sport of Ruiz and Graupera (2005) was applied to measure aspects of decision making in sports. Among the most relevant aspects is the commitment to their training. It combines not only the concern for the adversary, for knowing their customs and their concerns in the competition, but clearly emphasizes the importance of relying on the coach's tactical plan and following his instructions. The results analyzed with the Mann-Whitney $\mathrm{U}$ test show that there are no differences in the decision profile between genders; however, it was determined that the men presented themselves to present perceived decision-making competence and commitment to decisionmaking than women, plus, they face less anxiety and stress when deciding. Therefore, it is concluded that the decision profile may be related to the competitive experience, since the men of the present study have shown better sports performance in previous meetings than women.
\end{abstract}


Keywords: Anxiety, Burden, Commitment, Decision profile

\section{Introduction}

The first studies on decision making in sport by Alain and Proteau (1980); Bard and Fleury (1976); Bard, Fleury, and Carrière (1989); Goulet, Bard, and Fleury (1989); and cited in García, Ruiz, and Graupera (2009) were preferably carried out in a laboratory with very controlled designs. Therefore, although the researchers' manifest intention was to explore cognitive processes relevant to the athlete, the experiments reproduced situations that were very distant from sporting reality. The work of Canadian researchers from the 70s and $80 \mathrm{~s}$, who were concerned with aspects such as visual processing or perceptual strategies of the subjects, could be taken as an example of this type of approach. In the study, García et al. (2009) found that volleyball male and female players have a very similar decision profile (no significant differences found) with a moderate perception of competition, low anxiety, and high commitment. Besides, as the level of sport increases, commitment and the perception of competition increase moderately, while anxiety about decisionmaking decreases considerably. As a consequence, the volleyball profile of the international level is considerably more closed than that of the lower sports levels.

Aguilar, Martín, and Chirosa (2013) concluded that making the right decisions during sports is one of the pillars of the correct development of the game. For this reason, from the basic training, it is vital to work out both the technique and the tactics and, in particular, the decision making. The development of tactical thinking should be oriented towards comprehensive learning that allows athletes to improve procedural knowledge of an explicit nature. Moreno, del Campo, Reina, Ávila, and Sabido (2003), cited in VilaMaldonado, García, and Contreras (2012), found as in other investigations that expert athletes present visual search patterns that respond to deliberate perceptual strategies, which influences when making a competing decision. On the other hand, the less-experienced ones present a visual search that obeys the order of occurrence of events.

The participation of students in sporting events is of great relevance to their life experience in terms of stimulating the acquisition of values, decision making, and personal and social responsibility among other factors. Most especially, this can be seen in competition which is the moment or fundamental aspect of the sports field. In this period, the athletes, despite having a good physical condition and optimal training, do not always score favorable results. There is uncertainty that these results are directly related to the decision making by players in the different sport disciplines. This is why the concern was born to carry out this research focused on a specific sport, 
volleyball, which is a sport of extreme skill and where each decision making takes place at a very short period. Also, when taking this sport's discipline for its specific analysis, the different variables related to the athlete's responsibility and emotions at the time of competition must not be left out. One of the fundamental characteristics of cognitive theory is to consider the athlete's actions regardless of context (Schmidt \& Lee, 1999).

Therefore, the training objective should be that the athlete acquires the greatest possible number of automatisms and possible stimulus-response situations (Balagué et al., 2008) to achieve ideal execution models. This approach is oriented to the full knowledge of the alternatives of action. The athlete is aware of their behaviors, their knowledge is stored in memory in the form of mental representations and, from here, they apply the information to consciously decide and execute. In the sports context, all this information is continually updated and stored in memory by configuring your knowledge base of a specific sport (Magill, 2007).

\section{Method}

\section{Subjects or sample}

In the present study, the UACH volleyball teams participated with a total of 24 players: 12 of them female and 12 male, both in an age range of 18 to 25 years.

\section{Research Design and Study Variables}

It is a descriptive-comparative study, which seeks to specify important properties and characteristics of any phenomenon analyzed, describes trends, and determines the differences between a group or population. In this case, it is comparison between genders.

\section{Independent Variable}

Gender: Understood as a nominal measurement level since it simply refers to the male and female categories without giving them any order or hierarchy (Coolican, 1997).

\section{Dependent Variables}

Perceived Decisional Competition: It refers to the perception that the athlete has of his competence to decide in his sport, both for the opinion that significant others may have of him and for his comparison with his teammates and opponents (Ruiz \& Graupera, 2005).

Anxiety and Stress when Deciding: It is a negative dimension of decision making since it refers to the circumstances that generate stress and the fears of the athlete related to the fact of deciding in his sport (Ruiz \& Graupera, 2005). 
Commitment in Decisional Learning: It is related to the responsibility and effort that the athlete manifests in improving their competence to decide and the tactical monitoring of the advice of their coaches (Ruiz \& Graupera, 2005).

\section{Instrument}

In this study, the Decision Style in Sports Questionnaire (CETD) by Ruiz and Graupera (2005) was used as a tool or instrument in field research. Also, an important benefit is obtained which is to highlight the existence of different aspects of the decision making in sports. Thus, this was highlighted and considered by the athletes themselves. Among the most relevant aspects in the commitment in their decisional training is the first-order element. It combines not only the concern for the adversary to know their customs and preferences in the competition but also the importance of relying on the coach's tactical plan and following his instructions.

\section{Process}

The steps to develop and obtain results of this project have the following sequence: Selection of the CETD questionnaire as a tool or instrument to gather required information among athletes. Coaches were asked for permission to conduct research with their athletes as well as observation during training and to apply the questionnaire. Subsequently, analysis and grouping of responses obtained according to the information provided by the athletes in the CETD questionnaire were carried out to enter the data into the SPSS STATISTICS program. This is in addition to performing the MANNWHITNEY U non-parametric test for two independent samples and obtaining results by applying the three different variables with a gender comparison.

\section{Results}

Once the field research was carried out using the different variables used, the following results or conclusions were obtained: no significant difference was found in the dimension of perceived decision-making competence. However, it can be observed that men tend to present a better response compared to women (Table 1.0 and Figure 1.0).

Table 1.0. Mann-Whitney U descriptive analysis in the perceived decision-making competence dimension between both genders.

\begin{tabular}{lllll}
\hline Género & Mediana & Ri & $\mathbf{Z}$ & $\mathbf{P}$ \\
\hline Femenino & 24.00 & $(16.75-28.75)$ & -1.535 & .125 \\
Masculino & 27.00 & $(23.00-30.00)$ & & \\
\hline
\end{tabular}




\section{Competencia Decisional Percibida}

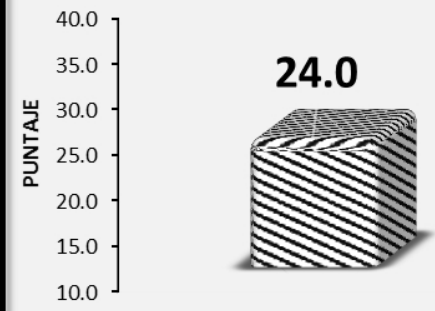

Femenino
27.0

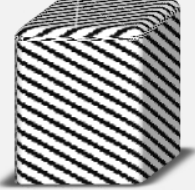

Masculino

Figure 1.0. Distribution of the mean in the perceived decisional competence dimension between genders.

There was no significant difference in the dimension of anxiety and stress when deciding. However, it can be seen that men tend to have a better response compared to women (Table 2.0 and Figure 2.0).

Table 2.0 Mann-Whitney U descriptive analysis in the anxiety and burden dimension when deciding between both genders.

\begin{tabular}{lllll}
\hline Género & Mediana & Ri & $\mathbf{Z}$ & P \\
\hline Femenino & 18.00 & $(13.25-22.25)$ & -.261 & .794 \\
Masculino & 16.00 & $(14.25-21.50)$ & & \\
\hline
\end{tabular}

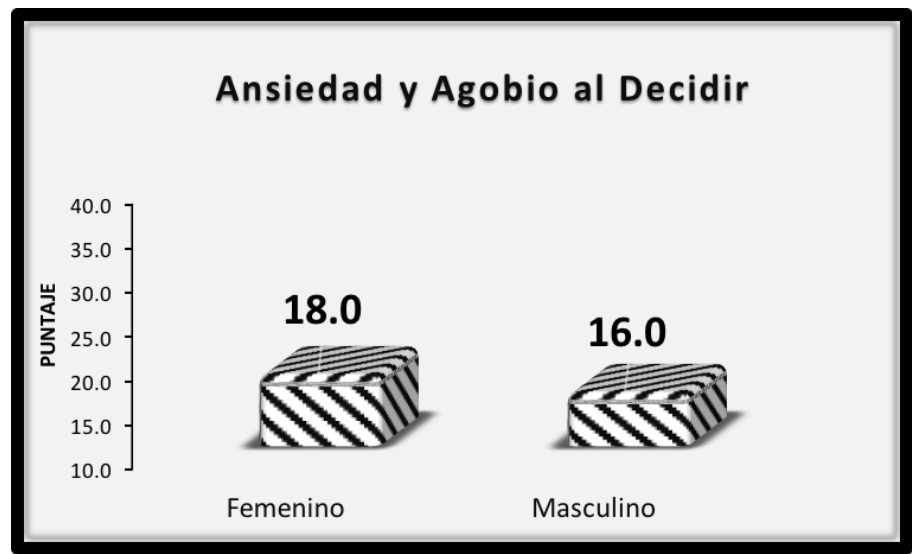

Figure 2.0. Distribution of the mean in the anxiety and burden dimension when deciding between both genders.

No significant difference was found in the dimension of commitment in decision learning. However, it can be seen that men tend to have a better response compared to women (Table 3.0 and Figure 3.0). 
Table 3.0. Descriptive analysis U of Mann-Whitney in the dimension of commitment in the decisional learning between both genders.

\begin{tabular}{lllll}
\hline Género & Mediana & Ri & $\mathbf{Z}$ & P \\
\hline Femenino & 32.00 & $(27.25-34.75)$ & -.435 & .664 \\
Masculino & 32.50 & $(30.25-34.00)$ & & \\
\hline
\end{tabular}

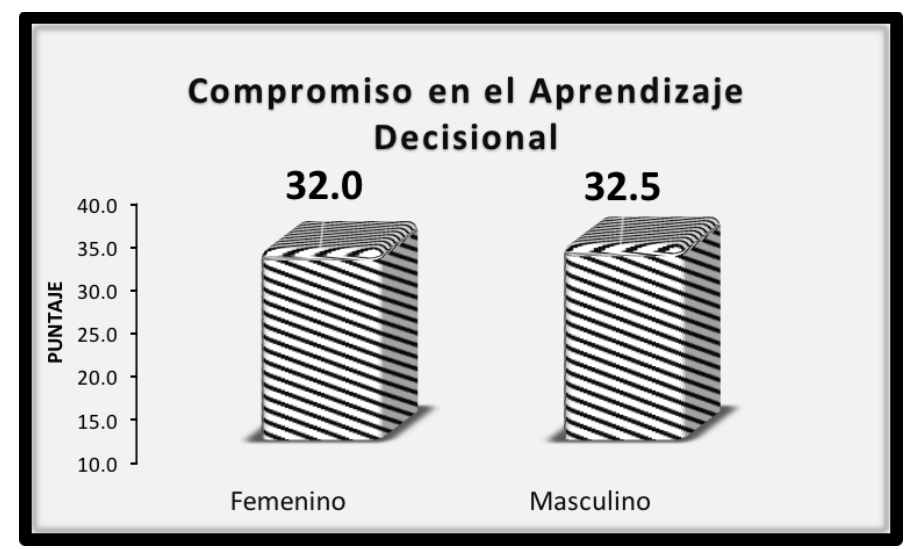

Figure 3.0. Distribution of the mean in the commitment dimension in decision-making learning between both genders.

As shown in the previous tables, there is no significant difference between both genders in the decision profile of volleyball athletes during periods of competition.

\section{Conclusion}

According to the results, the gender of the athletes is not a determining factor for the best decision making during competition. Well, although the same questionnaire was applied to both genders, there is no direct relationship between the results of the said study. According to the study of Claver, Jiménez, Fernández, González, and Moreno (2015) entitled "Procedural Knowledge and Decision-Making Profile of Volleyball Players of Child Category", the player's decision-making process during the course of an action/game can be influenced by numerous variables, which can be cognitive and emotional. These variables must be taken into account when planning training as far as decision learning is concerned. As a second comparison, based on the results obtained with those of the study by García et al. (2009) entitled "Decisional Profiles of Volleyball Players of Different Skill Levels", similar research was used in both investigations and their results are of great similarity. The comparison strengthens the results obtained in this research, since both show that women have a significantly lower perception of decisionmaking competence. As concluded in this field investigation, there are no 
significant differences between both genders at the time of deciding within the periods of competition. However, this research can be used for other similar studies, in which competitive experience in high-performance sports (number of participations in National Universities, international events, or finalist phases of these) is analyzed as a determining factor to improve the decision profile of the athletes within the competitions.

\section{References:}

1. Aguilar, J., Martín, I. \& Chirosa, L. J. (2013). Study of the subjective dimension of decision making in high school students through the Decision Style Questionnaire in Sports (CETD). Iberoamerican Journal of Exercise and Sports Psychology, 9 (1), 209-220.

2. Balagué, N., Hristovski, R., \& Vázquez, P. (2008). Ecological dynamics approach to decision making in sport. Training issues Education Physical Training Sport, 71 (4), 11-22.

3. Claver, F., Jiménez, R., Fernández, C., González, J., \& Moreno, M. (2015). Procedural knowledge and decisional profile of volleyball players in the children's category e-balonmano.com: Journal of Sports Sciences, 11.

4. Coolican, H. (1997). Research methods and statistics in psychology. Mexico: Modern Manual.

5. García, V., Ruiz, L.M., and Graupera, J.L (2009). Decisional profiles of volleyball players of different skill levels. International Journal of Sports Sciences 14 (5), 123-137.

6. Magill, R.A. (2007). Motor learning concepts and applications. New York, N.Y :: McGraw-Hill.

7. Ruiz, L. M. \& Graupera, J.L. (2005). Subjective dimension of decision-making in sport: development and validation of the CETD questionnaire of decision style in sport. European Journal of Human Movement, 14, 95-107.

8. Schmidt, R.A. \& Lee, T. D. (1999). Motor control and learning: A behavioural to emphasis (3 ed.).

9. Vila-Maldonado, S ., García López, L.M ., \& Contreras Jordán, O.R. (2012). The research of the visual behavior, from the cognitiveperceptual focus and the decision making in sports. Journal of Sport and Health Research. 4 (2): 137-156. 